\title{
SEMIÓTICA LACANIANA E ORIGEM EM MARTHE, DE HUYSMANS: NOTAS PARA UMA TRADUÇÃO CRIATIVA
}

\section{LACANIAN SEMIOTICS AND ORIGIN IN HUYSMANS' MARTHE: NOTES FOR A CREATIVE TRANSLATION}

RESUMO: Este artigo aborda o romance Marthe, de Huysmans, à luz da semiótica de origem lacaniana com um propósito tradutório. Após a definição do nó borromeano e dos matemas para metáfora e metonímia, abordamos também o conceito de origem (Ursprung) benjaminiano em comparação com a ideologia e a reificação. Analisando o texto, identificamos um personagem ligado à fantasia e outro, à perversão e separamos o significante do beijo que, metaforicamente, leva-nos ao significante da pérola, identificado com o falo imaginário. Na construção de um poema constitutivo do livro, isolamos o significante-mestre, um significante sem significado, /dã/. Articulamos uma versão para o português que se origine de um significante-mestre, agora traduzido como /tã/, e elencamos algumas características do falo imaginário.

PALAVRAS-CHAVE: Marthe; Huysmans; Semiótica; Lacan; Tradução.

ABSTRACT: This article approaches Huysmans' novel Marthe under the light of the semiotics of lacanian origin with the purpose of a translation. After defining the borromean knot and the mathemes for metaphor and metonym, we also approach the benjaminian concept of origin (Ursprung) in comparison with ideology and reification. Analyzing the text, we identify one character linked to fantasy and another one to perversion, and we separate the signifier of the kiss which, metaphorically, takes us to the signifier of the pearl, identified with the imaginary phallus. In the construction of a poem constitutive of the book we isolate the master-signifier, a signifier with no signified, /dã/. We articulate a version for the Portuguese that originates from a master-signifier now translated as /tã/ and we list some characteristics of the imaginary phallus.

KEYWORDS: Marthe; Huysmans; Semiotics; Lacan; Translation.

\footnotetext{
${ }^{1}$ Estudou Ciências Sociais e Letras Português na UFPR- Universidade Federal do Paraná e trabalha, atualmente, como tradutor e editor.
} 


\section{INTRODUÇÃO}

Não é exagero afirmar que, desde Freud, Lacan é o nome mais proeminente da psicanálise. De fato, o teórico francês abriu caminhos não só dentro da psicologia como tal, mas também dos estudos literários, da sociologia, dos estudos sobre cinema e das humanidades em geral. Lacan também pode ter suas contribuições à teoria tradutória, e um de nossos propósitos, com este artigo, é explorar essa dimensão no trato de um texto de J. K. Huysmans, Marthe. O psicanalista que releu Freud estruturalmente trará, para essa obra do naturalismo francês, todo um conjunto "formular" com uma aplicação bastante prática, mas deixará, também, em aberto pontos importantes no terreno da teoria e paradigmas a serem aprofundados.

Abordaremos, inicialmente, o conceito de nó borromeano, topologia fundamental na psicanálise lacaniana e, com base nisso, desenvolveremos algumas características de sua semiótica. Antes de nos aproximarmos do texto, dialogaremos com alguns conceitos de Walter Benjamin, propondo uma definição de narrativa nos parâmetros das três ordens borromeanas e distinguindo-as de ideologia e reificação.

No texto de Huysmans, localizaremos elementos fantasmáticos e perversos, um significante narrativo e sua metáfora fálica e, por fim, o significante mestre que nos dará a alavanca para uma pragmática tradutória.

\section{CONCEITOS PRELIMINARES}

\subsection{A Semiótica Psicanalítica de Matriz Lacaniana}

\subsubsection{O Nó Borromeano}

Jacques Lacan é um pensador crucial na encruzilhada a que o freudo-marxismo chegou no século XX. Após infrutíferas tentativas de reunir en bloc a aparelhagem teórica dos dois grandes materialistas do século XIX, coube ao pensador francês um "retorno a Freud" à luz das descobertas estruturalistas que permitiu pontuar elementos para uma teoria materialista do sujeito. O núcleo teórico para essa compreensão de Lacan deve ser buscado no seu conceito de nó borromeano. Grosso modo, o nó borromeano é uma topologia composta de três anéis que são as três ordens: Imaginário, Simbólico, Real. Nenhum desses três anéis pode ser rompido sem que os outros dois se percam também, o que serve para mostrar a indissociabilidade fundamental dos três registros que compõem a subjetividade. Mais tarde, ao estudar a obra de Joyce, Lacan acrescentará um quarto elo, o chamado sinthome, que tem por propósito manter a coesão das três ordens e evitar, assim, o precipício psicótico. Mas, por ora, devemos atentar para as três principais esferas do nó borromeano. Principiaremos pela imaginária.

A etologia de animais tão diversos quanto o gafanhoto migratório e a pomba o primeiro precisa ver a imagem de um membro da mesma espécie (de qualquer gênero ou até de si mesmo refletida) para passar à forma gregária; o segundo, também para a maturação das gônadas - indica que o chamado "estádio do espelho", no infante humano, é uma etapa fundamental em que o mundo interno e o externo encontram um liame. A partir dos seis meses de idade (que corresponderia, segundo Freud, à chamada fase anal), a criança passa a se interessar pelo reflexo de si mesma e começa a formação da ordem do Imaginário. 
O Imaginário - lugar da alteridade ainda subjetivamente alcançável, isto é, do outro com "o" minúsculo - está relacionado a um movimento em dois tempos (homólogo ao (des)conhecimento ideológico).

Em um primeiro momento a criança, perante o espelho, identifica-se com outro imaginário: há uma alienação do ego. Segundamente, percebe algo, denominado por Lacan como um eu-ideal, uma totalidade "mais completa" do que realmente é: há um não reconhecimento do ego como alienado.

[...] o ponto importante é que essa forma situa a instância do $e u$, desde antes de sua determinação social, numa linha de ficção, para sempre irredutível para o indivíduo isolado - ou melhor, que só se unirá assintoticamente ao devir do sujeito, qualquer que seja o sucesso das sínteses dialéticas pelas quais ele tenha que resolver, na condição de $E u$, sua discordância de sua própria realidade. (LACAN, 1999, p. 98, grifos do autor).

Um conflito é gerado entre o self fragmentado da criança e sua totalidade imaginária que Lacan traduz, com Hegel, para a dialética do mestre e do escravo. De maneira bastante geral, ela diz respeito a um relato na Fenomenologia do espírito a respeito da necessidade de superar a dominação, visto que o escravo (que existe para o outro) e o mestre (que existe para si mesmo) seriam dois lados da mesma consciência. Tal dialética concerne uma luta entre o mestre e o escravo - um, o pior inimigo do outro -, porém a morte de um será a morte do outro enquanto tal. Superar a identidade significa ascender ao reconhecimento, isto é, ingressar na ordem simbólica, no grande Outro.

Através da influência de estruturalistas tais como Lévi-Strauss na antropologia e Roman Jakobson na linguística, Lacan desenvolveu sua ideia de uma ordem simbólica que é o registro da linguagem, o lugar onde o sujeito é enredilhado numa teia de significantes. A diferença entre o (des)conhecimento do ego imaginário e a subjetividade que nasce na linguagem, pela qual o desejo é articulado, é que a violência narcisística no primeiro transforma-se num contrato na última.

Através da fala, reconheço o Outro [com "O" maiúsculo] [...] como o próprio locus da verdade (e da minha verdade), já que é necessário chamálo para testemunhar a verdade de minha fala, mesmo que seja para mentir para ele e para enganá-lo. Em outras palavras, o jogo da verdade pressupõe uma lei, uma regra do jogo [...]. (BORCH-JACOBSEN, 1991, p. 117, grifos do autor).

Ao contrário do pequeno outro, não se pode identificar com o grande Outro, pode-se apenas reconhecê-lo. Ele é organizado como uma linguagem, o que permite que as ordens sociossimbólicas (como uma narrativa literária, no caso deste artigo) sejam passíveis de serem estudadas como uma linguagem. Porém, antes de adentrarmos nos aspectos mais explicitamente semióticos da teoria lacaniana, precisamos salientar que o Outro é também o espaço do inconsciente. O Outro, que nunca é completo e sempre carece de algo, por essa mesma razão, dá possibilidade à existência do desejo humano: "o desejo do homem é o desejo do Outro." (LACAN, 2001, p. 292). Lacan concluiu daí que o inconsciente também é organizado como linguagem e pode ser estudado como tal (o que significa concomitantemente que, em estudos como os nossos, onde se aborda uma narrativa, pode-se e deve-se estar atento também aos "lapsos" inconscientes). 
Quanto ao Real, ele é o que existe antes e além da linguagem, é o registro onde nada falta e, por sua própria impossibilidade, por estar no limite da experiência humana, é o espaço também do limite dessa experiência.

A morte, a psicose e o trauma estão sempre ocupando o espaço do Real e ameaçam "retornar" violentamente sobre o indivíduo, estraçalhando a fantasia necessária para a sobrevivência. $\mathrm{O}$ anteparo fantasmático individual (que Lacan grafa em seus matemas $\$<>a$, isto é, o sujeito "barrado" e incompleto em relação com o objeto-causa do desejo), se rasgado, não consegue impedir que o indivíduo se afogue em jouissance. A jouissance difere em muito do prazer, pois este último obedece à busca da homeostase, ao passo que a primeira, que está além do princípio do prazer, é inerentemente transgressora e ligada ao instinto de morte. Tendo escrutinado os registros do Real, Simbólico e Imaginário, podemos passar ao aspecto mais nitidamente semiótico da teoria lacaniana.

\subsubsection{Elementos da Semiótica Lacaniana}

Para o linguista francês Ferdinand de Saussure, pensador crucial nas ciências humanas do século XX, a unidade mínima da língua era o signo, que, como uma folha de papel, era composto de dois "lados": o significante e o significado. Saussure (2003) atribui a essa relação significante/significado a propriedade da arbitrariedade.

Jacques Lacan, de modo não de todo indistinto da inversão de Hegel por Marx, atribui a unidade mínima da linguagem ao significante. Caracteriza também o significante como produtor do significado. A representação do signo passa a ser esta:

\section{$\mathrm{S}$ \\ $S$}

Signo

Onde $\mathrm{S}$ é o significante, e $s$ é o significado. É importante notar que a barra agora separa os dois elementos: ao contrário do signo de Saussure, em que os dois lados se inter-relacionam, na concepção semiótica lacaniana, há uma clara demarcação significante/significado.

Para Jacques Lacan, que percebe uma rijeza na barra separatória entre significante e significado, a significação só pode ocorrer no ato metafórico, cujo conceito, devedor de Jakobson, liga-o ao paradigma, isto é, às relações in absentia. A metáfora, ligada ao processo de condensação descrito por Freud, mostra o movimento da repressão, fornecendo um modelo para a repressão do inconsciente: um significante é reprimido para debaixo da barra, tal qual descrito na fórmula lacaniana.

$$
f\left(\frac{\mathrm{S}^{\prime}}{\mathrm{S}}\right) \mathrm{S} \cong \mathrm{S}(+) s
$$


Onde $\mathrm{S}$ é o significante e $s$, o significado. No lado esquerdo, fora dos parêntesis, f de $\mathrm{S}$ é a função significante, e a substituição de um significante por outro em $\mathrm{S}$ 'S. Do lado direito, entre $\mathrm{S}$ e $s$, o símbolo (+), que representa o acréscimo do significado, o cruzamento da barra do algoritmo de Saussure.

A ideia por trás dessa formulação um tanto obscura é a de que há uma resistência inerente à significação na linguagem (a resistência que é simbolizada pela barra no algoritmo saussuriano). O significado não aparece espontaneamente, mas é o produto de uma operação específica que cruza a barra. A fórmula tem como propósito ilustrar a tese de Lacan de que essa operação, essa produção de significado, que Lacan chama de 'significação', só é possível através da metáfora. (EVANS, 1996, p. 115)

Se a metáfora diz respeito às relações paradigmáticas in absentia, a metonímia está ligada às relações sintagmáticas in praesentia. O encadeamento sintagmático é também o movimento do desejo, a metonímia, a forma como adquire a busca humana pelo objet petit a (representado, na álgebra lacaniana, pelo a minúsculo), o objeto-causa do desejo que estimula o desejo, fazendo com que os instintos, por exemplo, circulem ao seu redor. Como no caso da metáfora, Lacan também propõe uma formalização algébrica para o caso da metonímia.

$$
\mathrm{f}\left(\mathrm{S} \ldots \mathrm{S}^{\prime}\right) \mathrm{S} \cong \mathrm{S}(-) s
$$

\section{Metonímia}

Do lado esquerdo temos o encadeamento de significantes que vai de $\mathrm{S}$ até S'. Porém essa sequência de significantes, por si só, não consegue cruzar a barra e gerar novo significado. A função significante da conexão de significante com significante é congruente com a manutenção da barra.

Toda ordem simbólica é faltante, castrada, barrada: a presença dessa falta é o pedaço do Real, a que Lacan dá o nome de significante-mestre e que é um significante sem significado. Esse significante-mestre, que Lacan grafa $\mathrm{S}(\mathrm{A})$, está relacionado à "castração da mãe". A criança, a qual percebe o Outro, a mãe, como completo em seus primeiros momentos de vida, passa pelo complexo de castração justamente ao perceber que a mãe também deseja desejo só pode existir onde há falta ${ }^{2}$.

\subsection{Origens Narrativas}

\subsubsection{Narrativa, ideologia, reificação}

Entendida dentro de nosso arcabouço teórico como uma predicação simbólica do Real, a narrativa possui essa qualidade contraditória e aparentemente paradoxal de simbolizar o não simbolizável, isto é, de suspender o Outro mediante o ato com que sempre-

\footnotetext{
2 Ao contrário de certos filósofos pós-modernos, dos quais destacaremos Foucault e sobretudo Deleuze, que veem numa presença o produtor do desejo (um fetiche, diremos), defendemos que é a falta no Outro que impulsiona a subjetividade em caminhos infinitos: a manque à être é o motor das ações humanas.
} 
já se constrói "em-si-e-para-si" no reconhecimento, mais do que em uma simples identificação. Este último movimento, ligado à esfera do imaginário, difere do reconhecimento propriamente simbólico onde o ser consciente-de-si existe perante o Outro.

Em ensaio ineludível sobre Nikolai Leskov (datando de 1936), o filósofo alemão Walter Benjamin argumenta que o narrador é uma figura em vias de desaparecer na modernidade, pois seria ligado indissoluvelmente ao tempo do trabalho artesanal. A reificação, fruto do trabalho industrial, a ideologia das informações fragmentárias, que se arrogam a posição de totalidade, e os efeitos nefastos da guerra, que se traduzem todos num empobrecimento da experiência (Erfahrung), contribuem para o desaparecimento paulatino da figura do narrador. O tempo moderno, destituído de sua potencialidade cairológica de narrar, pressionado pela produção capitalista, é contrário ao vagar em que um instante (weile) é percebido como longo (lange) pelo narrador e seus ouvintes, isso que seduzia o outro e reconhecia o grande Outro. Era um tempo de langor (Langeweile), do "pássaro de sonho que choca os ovos da experiência." (BENJAMIN, 1996, p. 204).

O tempo artesanal, livre da racionalidade reificatória, segue o argumento benjaminiano, permitia articular o nó borromeano pela existência da quarta ordem, o sinthome, que socialmente pode ser entendida como a presença do narrador que realiza e suprime os conflitos; já que experiência e narrativa estão em espaços objetivos diferentes e têm intenções subjetivas distintas, a experiência talha a história, e a história incorpora a experiência contada.

No tempo de trabalho industrial, ao contrário, o tempo de trabalho alienado é a inversão simbólica do tempo de lazer alienado. Trabalhando ou folgando, o indivíduo sob o capitalismo está à mercê da mercadoria, e as narrativas trazem, no seio, esse núcleo traumático que transforma o campo narrativo em campo de batalha.

É a vida real de um narrador que urde seus dramas. O Real - isso que "distingue o homem dos animais" e "estimula o dinamismo da condição humana" (ŽIŽEK, 1997, p. 95) - é o lugar de tra(u)ma. Os casos limites que compõem o Real ameaçam voltar sobre o indivíduo obliterando sua proteção fantasmática e afogando-o com a mortal jouissance (o prazer paradoxal buscado que está próximo da morte). É a morte que está na origem (Ursprung) da Narrativa. O narrador fala, portanto, com uma autoridade real, ainda que problemática. Para lançar luz sobre o conceito que usamos de narrativa ao longo deste artigo, cumpre contrastá-lo com dois outros conceitos da tradição materialista: a ideologia e a reificação.

Se a narrativa é uma predicação simbólica do Real, a ideologia é também uma predicação do Real, mas imaginária. Nesse sentido, ela está ainda presa à dialética do Mestre e do Escravo de identidade, do "em-si" e do estádio do espelho.

No clássico paradigma marxiano, as classes possuem suas consciências na medida em que estão inseridas dentro do processo material de produção. $\mathrm{Na}$ metáfora tradicional, a base (as forças materiais de produção) condiciona a superestrutura (as relações sociais). Proporemos o seguinte axioma: o Estado é o elemento responsável pela reprodução das condições de produção. Consequentemente, trata-se de reproduzir os meios de produção e a força de trabalho. Ora, para que a força de trabalho seja reproduzida é preciso assujeitá-la à dominação, seja pela repressão física, seja pela dimensão ideológica.

O Estado compõe-se, portanto - e aqui estamos dialogando explicitamente com o ensaio Ideologia e Aparelhos Ideológicos de Estado, do teórico francês Louis Althusser, escrito em 1969 -, de uma instância repressiva, que atua pela violência corporal, e de uma instância ideológica. Esta última é muito mais eficiente do ponto de vista da 
reprodução capitalista, porque mantém os corpos intocados e, portanto, capazes de gerar maisvalia. A ideologia existiria dentro de diversos aparelhos ideológicos de Estado (AIEs) - a religião, a escola, a família, o sistema jurídico, o sistema político, os aparelhos sindicais, as manifestações culturais - onde o corpo seria moldado de sua interioridade para fora a fim de obedecer ao "circuito" daquele aparelho.

Mas, quanto à Ideologia enquanto forma geral, onde se verifica um processo semelhante de méconnaissance como nos dois momentos do estádio do espelho, há um elo que unifica esses dois momentos a que Althusser dá o nome de interpelação.

\begin{abstract}
Observa-se que a estrutura de qualquer ideologia, ao interpelar os indivíduos como sujeitos em nome de um Sujeito Único e Absoluto, é especular, ou seja, é uma estrutura em espelho, e duplamente especular: essa duplicação em espelho é constitutiva da ideologia e garante seu funcionamento. O que equivale a dizer que toda ideologia é centrada, que o Sujeito Absoluto ocupa o lugar singular do Centro e interpela a seu redor a infinidade de indivíduos a se tornarem sujeitos, numa dupla relação especular, de tal ordem que sujeita os sujeitos ao Sujeito, ao mesmo tempo que lhes dá, no Sujeito em que cada sujeito pode contemplar sua própria imagem (presente e futura), a garantia de que isso realmente concerne a eles e a Ele [...]. (ALTHUSSER, 1999, p. 137, grifo nosso).
\end{abstract}

Tal qual no estádio do espelho em que se processa a alienação do ego e, posteriormente, o ocultamento dessa mesma alienação, o (des)conhecimento (méconnaissance) atua também no momento da interpelação ideológica em que o indivíduo vê o Mim que conhece (mé-connaissance) no limiar de transformá-lo em sujeito ao Sujeito. Contudo o indivíduo também é simbólico e, como tal, à mercê do enigmático Outro, cujo (en)jeu-des-mots desloca suas certezas ao mesmo tempo em que permite a existência do desejo.

Dessa forma, gostaríamos de sugerir o neologismo contraduzir para propor a relação do indivíduo com as diversas interpelações ideológicas com as quais se depara sem, necessariamente, ser reduzido à sua dimensão unicamente imaginária: o indivíduo tem atos e atividades que traduz com a interpelação que lhe é dirigida e também contra aduz ao Sujeito suas razões ${ }^{3}$.

Uma crítica pertinente a Althusser e importante no atual contexto diz respeito à redução do indivíduo a simples ego. Em outras palavras, a interpelação ideológica nem sempre é "perfeita", e os indivíduos não são, ao contrário do modelo esquemático althusseriano, mônadas autômatas. Althusser subsume o simbólico ao imaginário, e seus sujeitos, mansos e plácidos, desconhecem o que seja desejo, o que, na prática, tem efeitos políticos nefastos. Tendo contraposto ideologia à narrativa, iluminando este último conceito por oposição, podemos ex nunc ramificar a compreensão narratológica ao introduzir uma subnarrativa particularmente relevante: a reificação.

Com a transformação das subjetividades em elementos percebidos como objetivos pela introdução da racionalidade técnica nos ambientes de trabalho e nos AIEs em

\footnotetext{
${ }^{3}$ Como sugere Žižek (1999), um bom exemplo de subjetividades interpeladas, diferentemente de Althusser, encontram-se nas obras de Kafka: o processo, o castelo, são todos aparelhos que interpelam K, mas sem que este se identifique totalmente. É o reino do deus ausente.
} 
geral, a dimensão propriamente qualitativa da experiência humana se vê escamoteada, ainda que ressurja sintomaticamente nas crises "inexplicáveis" do capitalismo. Dessa maneira, o fetichismo é o fenômeno mediante o qual um objeto sensível é percebido como suprassensível, mágico, incompreensível; por contraste, a reificação é o fenômeno através da qual a subjetividade é transformada num objeto, artigo, coisa. Quando essa falsa objetividade impede os indivíduos de compreenderem a dimensão qualitativa do mundo, a ordem sociossimbólica se torna "dissociada", feito um fato da natureza ou de uma vontade divina. A reificação é esse fenômeno que recria a sociedade à imagem e semelhança da mercadoria. "A reificação exige que uma sociedade aprenda a satisfazer todas as suas necessidades em termos de troca de mercadorias." (LUKÁCS, 1997, p. 91).

Se o mecanismo psicológico par excellence no capitalismo do século XIX era a repressão, proposição verificável na razão desproporcional de pacientes neuróticos e de histéricas entre os pacientes de Freud, por exemplo, o caráter reificatório das relações sociais alienadas está vinculado indissociavelmente à categoria clínica da perversão (que Lacan grafa como o inverso da fantasia, no matema a $<>\$$ ), elemento que se encontra, dialeticamente, no produto e no produtor do capitalismo tardio. Enquanto, na neurose, trata-se de uma repressão da castração (o indivíduo atira o traumático ao inconsciente) e, na psicose, de uma foraclusão (onde se expulsa o traumático da realidade), a operação tipicamente perversa, tal qual descrita tradicionalmente na psicanálise, é a renegação (Verleugnung). Para Freud (2007):

Não é verdade que, depois de a criança ter feito sua constatação a respeito da ausência do pênis na mulher, ela tenha resgatado intacta sua crença de que as mulheres possuam um falo. Ocorre que a criança ao mesmo tempo manteve essa crença, mas também a abandonou. No conflito entre o peso da percepção indesejada e a força de seu contradesejo, ela chegou a um compromisso imaginário [...] o horror à castração levou o fetichista a erguer - por meio da criação desse substituto - um monumento que não deixa esse horror ser esquecido e convoca com maior intensidade ainda esse interesse antes voltado ao pênis. (p. 162-163).

O perverso, ao mesmo tempo, identifica e nega. A reificação torna-se, portanto, uma justificativa simbólica do Real. Como a narrativa, ela é uma simbolização, porém construída para sempre-já defender e escusar o curso do mundo (Weltlauf). Nesse sentido, ela procura, "fetichisticamente", cobrir o significante-mestre de cada ordem sociossimbólica, já que isso mostraria a "castração" do Outro, seus hiatos e brechas inerentes. É uma narrativa que contraduz seu desejo de tal modo que não consegue sustentá-lo. O que carece na ordem sociossimbólica é o que possibilita que o indivíduo identifique, com ele, seu desejo, por sua própria hiância fundamental.

De tal forma, podemos afirmar que uma narrativa pode ou não ser perversa. Diremos que é perversa se é tal simbolização que busque justificar o Real, "preencher o Outro"; diremos, por outro lado, que uma narrativa pode ser fantasmática, sendo assim capaz de sustentar o desejo. A fantasia é a cama onde o desejo se deita. Isso, claro, não muda o fato de que existe uma multiplicidade de gêneros narrativos, especialmente porque nossa definição é ampla o suficiente para abarcar elementos que, numa crítica literária tradicional, não seriam abordados. Resta saber como definir um gênero narrativo nos parâmetros aqui adotados. 


\subsubsection{Origem nos Gêneros Narrativos}

A tarefa de definição de um gênero encontra dificuldades tanto de ordem operacional quanto epistemológica. É possível dizer que pelo menos dois paradigmas - que refutaremos em prol de uma prática de outro nível - apresentam-se metodologicamente como abordagens à altura da missão e, ainda que não se mostrem explicitamente nos termos utilizados neste trabalho, disputam teoricamente um campo, por si só, já bastante controvertido, tanto nos experimentos de uma semiótica aplicada quanto na percepção da filosofia da arte. Uma via indutiva, "nominalista", buscaria analisar todas as obras reais de um dado gênero, buscando extrair, desse estudo pormenorizado, leis, conceitos e a própria definição do gênero - tal método corre, evidentemente, o risco de homogeneizar o seu objeto ao descartar o anômalo, para não dizer do procedimento prático disparatado. Outra via dedutiva, "realista", esforçar-se-ia para elaborar, a priori, um conceito minimamente razoável de seu gênero e, depois, buscaria enquadrar cada exemplo empírico em sua cercadura conceitual - novamente, o procedimento descarta o excepcional e o singular em igual homogeneização, e a praticidade não é maior do que no outro paradigma. Aqui, trata-se de adotar uma compreensão que releve (Aufheben é o termo hegeliano) essas duas vertentes justamente ao ascender o que nessas duas metodologias é resíduo à pedra de toque, ao objeto extremo onde o conceito cresce suas raízes.

Essa abordagem busca a origem (Ursprung é o termo benjaminiano) que, longe de ser uma gênese, opõe um tempo infinitamente homogêneo a um tempo de intensidades em cada "agora". Cronos é parado pela memória em cáiros, o que faz o presente "pular" (sprung) para um passado onde não habita. Isto é, a intensidade do passado ao qual a narrativa se prende é assinalada pelo que o presente potencialmente conta. Se encontrarmos dois pontos extraordinários através dos quais se articulam seus elementos extremos, é possível elaborarmos o conceito analítico que permitirá escrutinar um gênero narrativo enquanto ideia. Esse é o procedimento que adotaremos ao ler Marthe de J. K. Huysmans.

\section{MARTHE DE J. K. HUYSMANS}

Marthe (obra publicada em 1876) foi o primeiro romance de J. K. Huysmans (1848-1907), uma incursão naturalista pelo tema da prostituição, que acabou por trazer a atenção do reconhecido Émile Zola ao escritor estreante. Publicado na Bélgica devido à censura francesa, seria seguido por Les Soeurs Vatard (1879) e levaria até o satanismo de LàBas (1891). Num movimento não dessemelhante ao de um August Strindberg, Huysmans converte-se ao catolicismo após suas experiências "decadentistas".

A trama de Marthe envolve três personagens principais: a própria Marthe, prostituta e atriz de cabaré; Ginginet, também ator de cabaré e alcoólatra; e Léo, jovem poeta. Após perder a filha e o marido para a pobreza, Marthe trabalha para um bordel de onde foge. É auxiliada por Ginginet que a coloca num espetáculo que organiza. Lá, chama a atenção de Léo, com quem começa um relacionamento amoroso. Porém os dois se separam com uma doença da mãe dele, e, perseguida pela polícia da moral, Marthe pensa no suicídio. É dissuadida por Ginginet e passa a trabalhar para ele, que dela abusa. Fugindo dele, é apresentada por uma amiga a um rico playboy que a toma por amante. Mas logo Marthe se frustra e busca Léo novamente. Após um último encontro, ela percebe a futilidade de tentar reatar o relacionamento. Ela, então, retoma sua vida de prostituição com vários homens, não sem antes encontrar Ginginet reduzido à miséria e mendigando. O livro conclui com amigos 
de Léo observando o corpo do indigente Ginginet sendo dissecado para ilustrar o alcoolismo e com um deles lendo uma carta do poeta que informa que irá se casar com uma moça, tendo rejeitado Marthe completamente.

Existem dois níveis nesse tipo de ficção: o nível do descrito e o nível do dito. Os dois são ainda níveis de significado, porém são uma primeira triagem na busca pelo significante mestre.

Indicaremos, portanto, em cada capítulo, se cada um dos personagens fala ${ }^{4}$ pelo menos uma vez. Junto, acrescentaremos um esboço formal, que logo discutimos.

\begin{tabular}{|c|c|c|c|c|c|c|c|c|c|c|c|c|}
\hline & C. 1 & C. 2 & C. 3 & C. 4 & C. 5 & C. 6 & C. 7 & C. 8 & C. 9 & C.10 & C.11 & C.12 \\
\hline Marthe & Sim & Não & Não & Sim & Sim & Não & Não & Sim & Sim & Sim & Sim & Não \\
\hline Ginginet & Sim & Não & Sim & Sim & Sim & Sim & Não & Sim & Sim & Não & Sim & Não \\
\hline Léo & Não & Não & Não & Sim & Sim & Não & Não & Não & Não & Sim & Não & Não \\
\hline Forma & \multicolumn{4}{|c|}{ Exposição } & \multicolumn{4}{|c|}{ Espelho da Exposição } & Ponte & Stretto & Ponte & Fim \\
\hline
\end{tabular}

Tabela 1 - Discurso Direto do Trio Principal nos Capítulos.

Nos primeiros quatro capítulos, identificamos uma exposição, um tema que é proposto. Interessantemente, do capítulo quinto ao oitavo, essa exposição é apresentada em sua forma reversa. Encontramos também uma "ponte" (para mantermos a analogia musical) que liga momentos diferentes na obra. O que nos chama a atenção aqui é o que chamamos de Stretto.

No contraponto musical, o Stretto é um trecho de superposição de tema e resposta, uma parte conclusiva executada mais rapidamente. O que nos chama a atenção em nosso Stretto é que é o único capítulo em que Léo e Marthe falam sem Ginginet. Trata-se do clímax, quando há o máximo de tensão. Examinemos mais de perto o capítulo décimo.

O capítulo principia com Marthe adquirindo um apartamento mobiliado a seu amante playboy e decorando-o com o gosto vulgar que Huysmans descreve minuciosamente. Seu amante é, então, mostrado como um ser insuportável, clown, vão, estúpido. Nisso, Marthe pensa em Léo, diametralmente oposto a esse homem. Uma noite, ela vai até o poeta, pretendendo passar ali por acaso. Mas Léo está esperando outra mulher, que toca a campainha. Marthe se atira ao pescoço de Léo e o chantageia para não abrir a porta. Marthe tenta acariciar e beijar Léo, sem conseguir nada da parte dele. Por fim, ela irrompe numa diatribe contra o gênero masculino. O ponto nevrálgico de seu discurso é o seguinte:

É a guerra afinal! Destruímos e pilhamos! Veja, você me falava outra vez de uma mulher, não consigo lembrar o nome, não sou entendida, que era uma estátua. Ela adquiriu vida, você me disse, com o beijo do homem que a havia feito; é o contrário atualmente, nós nos tornamos mármore quando eles nos beijam! (HUYSMANS, 2002, p. 64)

\footnotetext{
${ }^{4}$ Entendemos aqui essa expressão como puramente o discurso direto dentro do texto. O personagem Léo se "expressa" no primeiro e no último capítulo através de um poema e uma carta, mas como não se entende que está "falando" para alguém, não incluiremos tais manifestações.
} 
A referência mitológica aqui diz respeito a Pigmalião, que se apaixonou pela estátua que criara e, por intermédio de Afrodite, vê a estátua adquirir vida. No discurso de Marthe, há uma inversão em jogo.

Ou o beijo transforma objeto em sujeito, ou o beijo transforma o sujeito em objeto. Temos aqui a oposição entre fantasia e perversão traduzida no âmbito do livro pela oposição entre Léo e Ginginet. Podemos elaborar uma descrição e categorização dos 16 beijos descritos no romance.

\begin{tabular}{|c|c|c|c|c|}
\hline Núm. & Descrição & Capítulo & Fantasmático & Personagens \\
\hline 1 & Beijo de outros & 2 & Sim & Amigos de Marthe \\
\hline 2 & Beijo na mão & 4 & Sim & Marthe e Léo \\
\hline 3 & Beijo ao despertar & 4 & Sim & Marthe e Léo \\
\hline 4 & Beijo nos lábios & 4 & Sim & Marthe e Léo \\
\hline 5 & Beijo no pescoço & 4 & Sim & Marthe e Léo \\
\hline 6 & Beijo de despedida & 4 & Sim & Marthe e Léo \\
\hline 7 & Beijo de chegada & 4 & Sim & Marthe e Léo \\
\hline 8 & Beijo maternal & 5 & Sim & $\begin{array}{lccc}\text { Marte } & \text { e } \\
\text { (recordação) } & \text { sua } & \text { mãe }\end{array}$ \\
\hline 9 & Beijo efusivo & 5 & Sim & Marthe e Léo \\
\hline 10 & Beijo fingido & 8 & Não & Marthe e Ginginet \\
\hline 11 & Beijo afoito & 9 & Não & Marthe e Playboy \\
\hline 12 & Beijo de reconciliação & 10 & Sim & Marthe e Léo \\
\hline 13 & Beijo de incitação & 10 & Sim & Marthe e Léo \\
\hline 14 & Beijo refletido & 10 & - & Marthe - Pigmalião \\
\hline 15 & Beijo rememorado & 10 & Sim & Léo (Marthe) \\
\hline 16 & Beijo de adeus & 10 & Sim & Marthe e Léo \\
\hline
\end{tabular}

Tabela 2 - Beijos no Romance

Em meio a esses beijos, chama a atenção o beijo maternal no capítulo quinto, o único na lista entre pessoas do mesmo gênero e sem conotação sexual. Examinando mais proximamente esse capítulo, encontramos Marthe e Léo tentando morar juntos e encontrando 
diversas dificuldades. Léo recebe então uma carta que lhe informa da doença de sua mãe, e Marthe tem uma crise nervosa lembrando a sua. $\mathrm{O}$ trecho é o seguinte:

[...] à palavra 'mãe', ela havia sentido um golpe em seu peito. Sua infância, que ela buscava não sondar, subitamente lhe reaparecia, e ela revia sua mãe morta, debruçando-se sobre seu berço, beijando suas mãos quando ela as tirava das cobertas, sorrindo-lhe com lágrimas quando o quarto estava frio. (HUYSMANS, 2002, p. 37)

Encontramos, aqui, mais um significado acrescentado ao beijo, trata-se do beijo com lágrimas. Recordando-nos da formalização para a metáfora, podemos aplicar ao significante o significado que acabamos de descobrir para localizarmos uma metáfora do beijo:

\section{Equação 1 - Fórmula da Metáfora aplicada ao Beijo}

\section{$f\left(\frac{\text { pérola }}{\text { beijo }}\right)$ beijo $\cong$ beijo $(+)$ lágrima}

No capítulo segundo, o narrador nos informa que Marthe era filha de Sébastien Landousé, um pintor, com Florence Herbier, artesã de pérolas artificiais. Ele morre cedo e na pobreza, e a mãe de Marthe a instrui no ofício. Huysmans descreve com todo o detalhamento realista/naturalista o processo de fabricação dessas pérolas ${ }^{5}$.

A pérola é o significante fálico do livro. A "pérola" mais evidente (no sentido de um registro poético) é justamente o poema de Léo para Marthe no primeiro capítulo. Poema que será "invertido" no último capítulo com sua carta (em prosa) para seu amigo. Examinemos, mais de perto, o poema do primeiro capítulo escrito por Léo para Marthe, ao qual acrescentamos uma tradução de nossa própria lavra.

\begin{tabular}{|c|c|c|}
\hline À une chanteuse (HUYSMANS, 2002, p. 6) & Rima & Ordem \\
\hline Un fifre qui piaule et siffle d' un ton sec, & $/ \varepsilon \mathrm{k} /$ & Simbólico \\
\hline Un basson qui nasille, un vieux qui s' époumonne & /on/ & Simbólico \\
\hline À cracher ses chicots dans le cou d' un trombone, & /on/ & Simbólico \\
\hline Un violon qui tinte ainsi qu'un vieux rebec, & $/ \varepsilon \mathrm{k} /$ & Simbólico \\
\hline
\end{tabular}

\footnotetext{
${ }^{5}$ A respeito desse trecho, o tradutor inglês Brendan King nos informa que Huysmans havia sido levado a uma fábrica de pérolas artificiais por seu amigo Ludovic de Francmesnil (HUYSMANS, 2006, p. 136).
} 
CASA, Vol.8 n.1, agosto de 2010

\begin{tabular}{|l|l|l|}
\hline & & \\
\hline Un flageolet poussif dont on suce le bec, & $/ \varepsilon \mathrm{k} /$ & Simbólico \\
\hline Un piston grincheux, la grosse caisse qui tonne, & $/ \mathrm{n} /$ & Simbólico \\
\hline Tel est, avec un chef pansu comme une tonne, & $/ \mathrm{s} /$ & Simbólico \\
\hline Scrofuleux, laid enfin à tenir en échec & $/ \varepsilon \mathrm{k} /$ & Simbólico \\
\hline La femme la plus apte aux amoureuses lices, & & \\
\hline L'orchestre du théâtre - et c'est là cependant & $/ / \mathrm{lis} /$ & Simbólico \\
\hline Que toi, mon seul amour, toi, mes seules délices, & $/ \mathrm{d} \tilde{\mathrm{d}} /$ & Simbólico \\
\hline & $/ / \mathrm{lis} /$ & Simbólico \\
\hline Tu brames tous les soirs d'infâmes ritournelles & & \\
\hline Et que, la bouche en coeur, l'oeil clos, le bras pendant, & $/ \mathrm{d} \tilde{a} /$ & Real \\
\hline Tu souris aux voyous, ô la reine des belles ! & $/ \varepsilon \mathrm{l} /$ & Simbólico \\
\hline
\end{tabular}

Tabela 4 - Poema de Léo a Marthe no Capítulo 1

\section{Poema de Léo a Marthe no Capítulo $1^{6}$}

\section{A uma cantora}

Um pife pia e silva com voz seca,

Um baixo é fanho e um velho vai com dor

Cuspir num trombone seu interior.

Zumbe um violino feito rebeca,

Um flajolé dispneico alto impreca,

Um pistão ranzinza, um bumbo dá cor.

Barril é o maestro sem tirar nem pôr,

Escrofuloso, feio sem que impeça

Mulher mais apta à arena da afeição,

A orquestra do teatro - e entrementes,

Que tu meu só amor, só fruição,

\footnotetext{
${ }^{6}$ Nossa tradução para o português.
} 
Bramas às noites sujos ritornelos,

D’alma os lábios, cega, braços pendentes,

Sorrindo aos vadios, rainha dos belos!

Chama a atenção que o poema todo é um contínuo encadeamento (enjambement), alegoricamente como o romance existe só na medida em que os capítulos formam uma unidade superior, uma "pérola".

Notamos que apenas a rima /dã/ está relacionada a um registro do Real. Isso porque, no verso correspondente, o corpo é descrito ambiguamente, podendo ser o de Marthe enquanto está no palco (o primeiro sentido do texto), mas também o corpo no ato sexual (a jouissance) e o corpo morto, o que caracteriza o registro do Real. Diremos que a sílaba /dã/ é o significante mestre, um pedaço do Real, significante sem significado.

\section{DISCUSSÃO}

Na teoria lacaniana, o falo não deve ser confundido com o órgão genital masculino. O falo é, sobretudo, um significante particularmente privilegiado que opera nos três registros - Real, Simbólico e Imaginário - indicando a diferença sexual.

Ao perceber que não é o único objeto do desejo de sua mãe, a criança tenta retornar ao estado de união inicial fazendo-se passar pelo objeto de desejo da mãe. Esse objeto que a criança acredita que a mãe deseja (criando assim uma tríade mãe-criança-objeto desejado) é chamado de significante fálico.

O falo imaginário é o que a criança assume que alguém deve ter para que seja o objeto do desejo da mãe e, como seu desejo é geralmente dirigido para o pai, assume-se que ele possui o falo. Ao tentar satisfazer o desejo da mãe, a criança se identifica com o objeto que ela presume que ela [a mãe] perdeu e tenta se tornar esse objeto para ela. O falo é imaginário no sentido de que é associado na mente da criança com um objeto real que foi perdido e pode ser recuperado. (HOMER, 2005, p. 55)

Lacan grafa, em seus matemas, o significante fálico imaginário como $\varphi$ (Phi minúsculo). Podemos resumir nossos resultados no estudo do texto da seguinte forma:

$$
\begin{gathered}
\mathrm{S}(\mathrm{A})=/ \mathrm{dã} / \\
\$<>\mathrm{a}=\text { Léo } \\
\mathrm{a}<>\$=\text { Ginginet } \\
\varphi=\text { pérola }
\end{gathered}
$$

Uma ordem simbólica tem por base sempre seu significante-mestre. Se uma tradução é uma ordem simbólica em relação à outra ordem simbólica, faz sentido fundar a ordem simbólica do texto traduzido com um $\mathrm{S}(\mathrm{A})$ em relação ao outro $\mathrm{S}(\mathrm{A})$.

Tomemos um exemplo: no capítulo décimo do livro, que associamos a um stretto no contraponto do enredo, surge $\mathrm{S}(\mathrm{A})$ no meio da palavra "cependant". A frase é esta: 
"Il avait décidément assez d'elle, elle lui répugnait depuis qu'il connaissait sa manière de vivre, il la jugeait méprisable entre toutes, et cependant comment éviter la pipée de ses yeux, comment échapper à l'affût de sa bouche ?" (HUYSMANS, 2002, p. 64).

Tomamos, por origem (Ursprung) de nossa tradução, exatamente esta palavra - cependant.

Propomos a tradução "não obstante" e notamos que o $\mathrm{S}(\mathrm{A})$ /dã/ do francês tornou-se /tã/ na tradução. Recriamos toda a frase.

Ele estava decididamente farto dela, ela o repugnava desde que viera a saber de sua maneira de viver, julgava-a a mais desprezível entre todas, e não obstante como evitar seus olhos passarinhando, como escapar daquela boca à espreita?

Chamamos a atenção para a expressão "olhos passarinhando"; "pipée de ses yeux", no original, remete a uma caçada que se faz imitando o som de pássaros. Escolhemos o verbo "passarinhar", que tem tanto a acepção de fazer caçada de pássaros, quanto de vadiar, vagabundear e o tabuísmo "bolinar", o que recria a pérola excêntrica no texto de Huysmans.

Podemos, portanto, conceber uma Marthe cujo S(A) é /tã/, dotada de uma estrutura homóloga à da Marthe original. Desse modo, não se corre o risco de se querer traduzir o texto pelo significado, ao invés de recriar uma ordem simbólica a partir de um significante. Não há como copiar pérolas.

\section{CONCLUSÃO}

Neste artigo, vimos a semiótica psicanalítica de Jacques Lacan, tendo por base sua topologia do nó borromeano. Esse elemento é composto por três ordens (Real, Simbólico e Imaginário) que compõem a subjetividade. A ordem do Imaginário corresponde à fase do espelho, ao ego, à alteridade ainda apreensível. O reino do Simbólico, por sua vez, diz respeito à alteridade radical, ao Outro (com "O" maiúsculo), à ordem do inconsciente e da linguagem. Finalmente, o Real é inalcançável pela linguagem.

Após isso, abordamos a semiótica lacaniana que vê no significante o produtor do significado. Vimos como Lacan liga a metáfora às relações paradigmáticas e a metonímia às relações sintagmáticas. Identificamos um significante que não produz significado e que é a "ausência fundadora" de uma ordem simbólica, chamada de significante mestre.

Adentramos, então, pelo terreno da narrativa, que compreendemos como um ato simbólico que consegue predicar o Real. Nós a distinguimos da ideologia, que é uma predicação meramente imaginária, e salientamos como a reificação, uma justificativa simbólica do Real, pode compor uma narrativa também. Mostramos, contudo, que há uma diferença entre a narrativa perversa e a fantasmática e que apenas esta última sustenta o desejo.

Perguntamo-nos, então, a respeito da definição do gênero narrativo e, rejeitando a via indutiva e a dedutiva, propusemos, em diálogo com Walter Benjamin, a busca da origem. Com isso, abordamos a obra de Huysmans em cinco momentos.

Primeiramente, relacionamos o discurso direto de cada personagem em cada capítulo e percebemos, no capítulo décimo, um clímax.

Em segundo lugar, localizamos, nesse mesmo capítulo, o significante "beijo" como divisor entre o fantasmático (Léo) e o perverso (Ginginet). 
Em terceiro lugar, classificamos todos os beijos do romance e examinamos, mais proximamente, o beijo maternal.

Em quarto lugar, interpretamos a pérola (em cuja produção Marthe e sua mãe trabalhavam, fabricação descrita no capítulo segundo) como metáfora do beijo. A pérola é o falo imaginário.

Em quinto lugar, investigamos o poema do primeiro capítulo como uma pérola e nele identificamos o significante mestre, a sílaba /dã/.

Em nossa discussão, abordamos alguns aspectos do falo imaginário e também indicamos a possibilidade de recriar Marthe entendida como ordem simbólica pela fundamentação sobre outro significante mestre. Sugerimos a recriação tradutória do livro para o português através de um novo significante-mestre, /tã/.

Esperamos que este artigo possa não apenas sugerir uma tradução de Marthe, mas também ajudar a perceber alguns procedimentos na semiótica lacaniana. A localização do significante-mestre numa ordem simbólica é a alavanca para uma tradução criativa.

\section{Referências bibliográficas}

ALTHUSSER, L. Ideologia e Aparelhos Ideológicos de Estado (Notas para uma Investigação). In: ŽIŽEK, S. “Um Mapa da Ideologia”. Rio de Janeiro: Contraponto, 1996. p. $105-142$

BENJAMIN, W. Magia e Técnica, Arte e Política. São Paulo: Brasiliense, 1996

BORCH-JACOBSEN, M. Lacan: The Absolute Master. Palo Alto: Stanford University Press, 1991

EVANS, D. An Introductory Dictionary of Lacanian Psychoanalysis. Londres: Routledge, 1996

FREUD, S. Escritos sobre a Psicologia do Inconsciente, vol. 3. Rio de Janeiro: Imago, 2007.

HOMER, S. Jacques Lacan. Londres: Routledge, 2005

HUYSMANS, J. K. Marthe, Histoire d'une Fille. Paris: Edition du Boucher, 2002

Marthe: The Story of a Whore. Cambridge: Dedalus, 2006. Traduzido por Brendan

King

LACAN, J. O Estádio do Espelho como Formador da Função do Eu. In: ŽIŽEK, S. "Um Mapa da Ideologia”. Rio de Janeiro: Contraponto, 1996. p. 97-103

. Écrits : a selection. Londres: Routledge, 2001

SAUSSURE, F. Curso de Linguística Geral. São Paulo: Editora Cultrix, 2003.

ŽIŽEK, S. The Plague of Fantasies. Londres: Verso, 1997.

Como Marx Inventou o Sintoma? In: ŽIŽEK, S. “Um Mapa da Ideologia”. Rio de

Janeiro: Contraponto, 1996. p. 297-331. 